\title{
The Utility of Hybrid Promotion and Tenure Tracks for Dental School Faculty
}

\author{
Bernard J. Costello, D.M.D., M.D., F.A.C.S.; Kathy L. Marshall, D.D.S.; \\ Tara Schafer, D.D.S.; Scott Phillips, D.D.S.; Thomas C. Hart, D.M.D., Ph.D.
}

Abstract: The promotion and tenure process for faculty members varies, by design, for different disciplines, departments, and academic institutions. For many faculty members in U.S. dental schools, the process may thus appear nebulous and be difficult to navigate. In this article, we review the history, forces of change, and some of the mechanisms utilized for promotion and tenure of faculty in the health sciences, particularly for clinician-educators. Some institutions have successfully created hybrid tracks for clinician-educators in order to develop and recognize these faculty members' scholarly activity in addition to their clinical teaching. Hybrid tracks empower faculty members to successfully perform scholarly activities that realistically reflect institutional missions. The authors of this article conclude with a number of practical suggestions to enhance development and retention of faculty using the hybrid promotion and tenure mechanism. These include demonstrating the congruence of institutional mission, faculty activities, and promotion and tenure guidelines; developing scholarly activities for clinician-educators that can be measured in the promotion and tenure process; rewarding scholarly achievement for clinician-educators utilizing the promotion and tenure mechanism; and developing an evaluation system that accounts for changes in mission and faculty activities.

Dr. Costello is Professor and Program Director, Department of Oral and Maxillofacial Surgery, School of Dental Medicine, University of Pittsburgh; Dr. Marshall is Clinical Director, Department of Orthodontics and Dentofacial Orthopedics, College of Dentistry, Howard University; Dr. Schafer is Interim Chair, Department of Pediatric Dentistry, School of Dentistry, Georgia Health Sciences University; Dr. Phillips is Associate Professor, Department of Care Planning and Restorative Sciences, School of Dentistry, University of Mississippi; and Dr. Hart is Head, Department of Periodontics and Director of Clinical Research, College of Dentistry, University of Illinois at Chicago. Direct correspondence and requests for reprints to Dr. Bernard J. Costello, School of Dental Medicine, University of Pittsburgh, 3471 Fifth Avenue, Kaufman Bldg., Pittsburgh, PA 15213; 412-648-6801 phone; 412-648-6835 fax; bjc1@pitt.edu.

Keywords: dental faculty, faculty development, clinical faculty, tenure, promotion

Submitted for publication 5/31/12; accepted 8/22/12

$\mathrm{T}$ The promotion and tenure process for faculty members varies, by design, for different disciplines, departments, and academic institutions. For many faculty members at North American dental schools, the process may thus appear nebulous and be difficult to navigate. In this article, we review the history, forces of change, and some of the mechanisms utilized for promotion and tenure of faculty members, particularly clinician-educators. We use the term "clinician-educator" to refer to faculty members who spend the majority of their time in direct contact with students and patients in the classroom and the clinic. ${ }^{1}$

We have assessed difficulties faculty members encounter in navigating the promotion and tenure process. After discussions with faculty members and evaluating the guidelines at sixteen institutions, we offer a number of considerations that may facilitate development and implementation of promotion and tenure guidelines that will help faculty members navigate the promotion and tenure process in conjunction with faculty development. This review was performed by the coauthors when they were participants in the American Dental Education Association (ADEA) Leadership Institute.

\section{Background}

Dental schools often require faculty members to devote considerable effort to teaching and patient care, thus decreasing the time available to engage in the research that is a key metric of conventional promotion and tenure guidelines. The proportion of tenured faculty at health science schools has decreased steadily and significantly over the last thirty years. ${ }^{2}$ Faculty members have undertaken larger commitments to teaching and clinical endeavors, creating an academic environment in which it is increasingly difficult for individual faculty members to 
successfully fulfill traditional research and scholarly activities needed to achieve promotion and tenure. ${ }^{3-5}$ At many dental schools, there is not a clear correlation among institutional mission, faculty effort, and promotion and tenure guidelines. However, many activities performed by dental faculty members can be developed to include scholarly outcomes. ${ }^{6,7}$

Hybrid tracks for clinician-educators have been successfully created by some institutions. These tracks are designed to develop and recognize scholarly activity in the four separate but overlapping categories of scholarship identified by Boyer: application, discovery, integration, and teaching. ${ }^{6,8}$ These tracks give more weight to clinical teaching, service, and other scholarly activities rather than relying on the more traditional metrics of federal funding received for research. Development of these scholarly activities can result in more effective teaching, training, and patient care, which are all principal goals of dental schools. ${ }^{1}$

\section{Importance of Promotion and Tenure}

Institutions grant promotion and tenure to individual faculty members on the basis of high achievement and recognition in scholarship, teaching, and service. Successful candidates must demonstrate that their accomplishments merit promotion and tenure. However, understanding and then navigating the promotion and tenure processes at universities can be confusing.

Charting a clear path to success can be particularly difficult for health science educators who have significant clinical and teaching responsibilities. From a junior faculty perspective, difficulties in successfully navigating the promotion and tenure process can be broadly defined as arising from two factors. First, promotion and tenure guidelines do not always correlate with the institutional mission and activities required of junior faculty members. Second, the process of being granted promotion and tenure is frequently not clearly explained to junior faculty members. Many are not mentored and often are not supported in ways such as protected time or resources that can enable them to develop the scholarly activities their efforts could produce. ${ }^{5}$ This may be particularly challenging at institutions that regard research as a primary mission for a faculty of educators charged with many duties such as teaching dental predoctoral and postdoctoral students, providing clinical care, and producing high-quality research. Compound- ing the lack of effective mentoring and support for faculty pursuit of scholarly activities, dental school faculty members are often not knowledgeable about the precise process involved in achieving promotion and tenure. ${ }^{9}$ Understanding and achieving academic advancement are important components of faculty satisfaction that require guidance from mentors and administrators to empower faculty members to move toward their goals. ${ }^{3,9-12}$

By design, the processes of promotion and tenure are not prescriptive to allow for different types of educators to gain advancement and recognition, based on varied activities and the inherent differences between universities, schools, departments, and divisions. This is precisely the reason why a list of metrics that would be accurate across all disciplines is impossible to create. Differences in the assessment methods used by evaluators, advisory committees, academic affairs offices, deans, and provosts sometimes create the appearance that promotion and tenure are not standardized or awarded in an equitable fashion-particularly across different disciplines. While it is appropriate and even helpful for there to be differences in opinion and interpretation of guidelines, the promotion and tenure guidelines should be consistent with activities faculty members are asked to perform in order to fulfill the institutional mission. ${ }^{1}$ Experienced mentors who understand the process can help junior faculty members develop a roadmap to build and integrate successful scholarly activities as an extension of their duties. Additionally, these mentors can help define the necessary resources that are needed to be successful. Such resources may include protected time, travel to meetings, local and national networking, staff support, and financial resources.

\section{Promotion and Tenure Tracks}

Traditionally, there have been two types of tracks: one for faculty members who are attempting to achieve tenure (tenure track) and one for those who can advance by promotion mechanisms but will not be awarded tenure (non-tenure track). Tenure is typically considered at the same time as promotion to associate or full professor. Most institutions place clinicians in the non-tenure track and have varied mechanisms for promotion for those faculty members who have sufficient academic activity. In the health sciences, the decision to enter into the tenure track is usually made based upon the faculty member's likelihood of achieving independent funding for research. The ability to achieve extramural research 
funding in a specific area of expertise often requires protected time and significant institutional resources (e.g., dedicated space, financial resources). Many individuals dedicated to teaching, clinical service, and/or administration do not have sufficient dedicated time or resources to achieve tenure within the typical time frame of five to seven years.

Because dental faculty members fulfill a wide variety of roles, it can be difficult to evaluate their efforts. How does one equate the scholarly success of a faculty member who has numerous research grants, has published in high impact journals, teaches infrequently, and practices clinical care infrequently to another faculty member who has an international reputation for innovative patient care, exceptionally busy clinical activities, numerous publications in well-known clinical journals, and outstanding teaching effectiveness evaluations but minimal external grant support? Both deserve formal recognition by their institutions for their impact on their field and contribution to fulfillment of the institutional mission. But how should this occur, and is the recognition they receive equal? More importantly, is the mechanism utilized by their institution equitable in the manner by which recognition and advancement are awarded? Traditional promotion and tenure guidelines at most dental institutions were developed in a previous era. Our discussions with dental school faculty members revealed that decreased research funding and changes in revenue streams at many dental schools have changed the environment in a number of ways. Decreased budgets now mean that fewer individual faculty members must do more, often with decreased staff support. Demands for increased clinical revenues have occurred at a time when students are demanding a higher quality education. These factors have had a dramatic impact on the daily activities of many clinician-educators.

In recent years, a variety of hybrid promotion and tenure tracks have emerged that attempt to serve the needs of faculty members with diverse roles and their inherently different academic activities. These tracks have been developed to recognize that the major activities of many faculty members have changed to meet evolving institutional priorities and missions. Hybrid tracks attempt to provide considerable weight to achievement in the scholarly areas of application, discovery, integration, and teaching, as outlined by Boyer and others. ${ }^{7,8,13,14}$ In these hybrid tracks, superior scholarly activity in these areas is considered as valuable as extramural funding for researchers and provides a mechanism for appropri- ate advancement. Some institutions award tenure using these mechanisms for individuals who achieve preeminence in these areas.

We think that hybrid tracks designed to provide weight to clinical and teaching activities in measurable ways serve to foster growth in the faculty and promote academic scholarship on a number of fronts. We believe that hybrid tracks are particularly helpful for dental schools, given the need for faculty members to perform in a number of areas with limited resources. As such, these mechanisms provide a much-needed reward and recognition of faculty, foster recruitment, and have the potential to improve retention of quality teachers, clinicians, and researchers. ${ }^{3,9,11,15,16}$

A key shift in the philosophy of scholarship at universities occurred with Boyer's introduction of broader definitions of scholarship. ${ }^{8}$ Boyer published these concepts of academic scholarship across multiple areas of activity that included application, discovery, integration, and teaching. ${ }^{8,17}$ These distinct yet overlapping concepts have helped form a framework for evaluating the academic activities of a variety of educators from literature scholars to academic clinicians. A number of authors in health care have extended these concepts to justify the academic activity of clinician-educators in a variety of medical and dental disciplines as varied as restorative dentistry, neurology, emergency medicine, surgical subspecialties, nursing, and others. ${ }^{12-14,18-20}$ The structure of hybrid promotion and tenure tracks is in many ways based on the same concepts that Boyer introduced to clarify scholarship across multiple areas of academic activity and give that scholarship value. As an example, in recognition of the changing demands on institutions and their faculties, Wake Forest University Medical Center developed six pathways that are reflective of its institutional mission. These pathways are education, clinical/education, research, clinician, clinical/research, and administrative/service.

\section{Forces of Change for Faculty Roles}

One of the most significant changes in health professions education over the last century has involved the duties of clinically active faculty members. The surgeon Williams Stewart Halsted is credited with being the force behind fundamental changes in clinical mentorship and scholarship at U.S. academic medical centers..$^{21}$ Halsted's expectations of a clinician-educator demanded that clinically active surgical faculty members not only teach 
surgery to their apprentices but also be scholarly. Scholarly activities such as publication and innovation are important elements in the development and translation of improved clinical approaches to patient care. The Flexner and Gies reports for medicine and dentistry, respectively, helped set the stage for changes in professional clinical teaching moving away from the apprenticeship model to the professionalization of medical and dental education. ${ }^{22-24}$ Academic health science centers and dental schools subsequently increased in size and number.

Early in the development of academic health centers, clinical revenue subsidized academic activities quite effectively, and the educator who was a clinician, teacher, and researcher was relatively common. Through the development of research universities and health science schools in the last two centuries, most have moved away from the apprenticeship model of education to institutions that focus on innovation and scholarly activity in the form of research, high-quality health care delivery to the public, and teaching that emphasizes these goals. A notable change has been the shift in the relative importance of clinical care as the revenue engine supporting other missions, such as research and teaching. As competition for research dollars has been diluted across multiple entities and state and federal funding has decreased, academic economics have become more difficult. Consequently, clinical revenue is increasingly depended upon to subsidize other activities. This shift has increased the proportion of faculty effort devoted to clinical duties and decreased the percentage of time allotted to scholarly activities. Faculty members who were required or chose to be more active clinically had less time and resources to perform research. ${ }^{3,25}$

Barchi and Lowery reviewed the changes in clinical-educator faculty members at the University of Pennsylvania School of Medicine and found clinical-educators shifted from 10 percent of the faculty population in 1978 to 58 percent in $1998 .^{3} \mathrm{At}$ the same time, the number of students taught actually decreased, indicating that more time was spent on clinical revenue generation than teaching and scholarly pursuits. While their analysis involved medical faculty members, the literature and our discussions support the idea that many of the same issues are experienced by other health sciences faculty members, including those at dental schools. Most recently, this ongoing fiscal trend has occurred at a time when state and federal funding for academic institutions has declined significantly. Additionally, acquiring federal research funding through the National Institutes of Health (NIH) has become significantly more difficult, with successful funding of applications currently around the 10 percent level. To be successful in the research arena typically requires significant (e.g., full-time) effort by investigators and the assignment of protected time and resources by the institutions. With deteriorating budgetary conditions, faculty members are increasingly required to choose one endeavor at the exclusion of the others, as time and finances do not allow pursuit of all aspects of mission fulfillment.

However, the demand for faculty members to produce scholarly activity has remained. Barchi and Lowery observed that, in the transitional period from 1978 to 1998 , tenure was rarely awarded to the clinician-educator faculty member, but promotion did occur when scholarly activity was considered worthy. ${ }^{3}$ These changes provided the impetus for creating a hybrid clinician-educator track to enable clinically active faculty members to achieve promotion in the more traditional promotion and tenure system. A ten-year tenure option also became available, and a variety of other institutions have put hybrid tracks in place. ${ }^{3}$ This shift in faculty duties and their emphasis over the past fifty years helped change the promotion and tenure process, so that the administration and university could appropriately mentor, support, evaluate, and award faculty members who spent a significant amount of time in clinical duties. ${ }^{3,25}$

Bickel's work reported similar trends in academic medicine faculty, noting that the perceived value of tenure was altered significantly as the guarantee of salary was only present in 12 percent of medical schools; most guaranteed only the base academic salary and made no guarantees relative to clinical incentives. ${ }^{26}$ As a result, more faculty members consciously make the choice to avoid the tenure stream requirements and timetable because of increasingly demanding clinical schedules. A study of new faculty members by Shepherd et al. found that tenure was not among the top five factors they had considered when taking a full-time faculty position in dental schools and was even less important regarding retention..$^{27}$ These forces of change have decreased the opportunity and incentives for traditional research and scholarly activity for many clinician-educators. Some authors have proposed that tenure has little or no value to clinician-educators. ${ }^{28-30}$ While changes such as post-tenure reviews and unlinking of financial guarantees are likely to modify its intrinsic worth in some institutions, many institutions value tenure 
and award it. We have chosen not to address this larger topic here, but we realize that some believe traditional tenure and its current value may not be present in future university policies in a way that serves clinicians well. It may be noted that if clinical faculty members feel tenure is not attainable, they are not likely to value it or view it as a professional goal.

In its original form, tenure was designed to provide productive and recognized faculty members with the academic freedom to write and produce scholarly work that would be relatively immune from penalty at their own institution if their views were not in line with those of their employer. ${ }^{28-31}$ This concept was designed to award job security and to provide a goal for junior faculty members to achieve that had significant academic and economic worth. Tenure has typically been awarded at the time of promotion to associate professor or professor. Non-tenure tracks were created to retain faculty members who would not typically be eligible for tenure, but were valuable to the university for a variety of reasons. However, as the missions of health sciences institutions have changed, the proportion of clinical-educator-type faculty members has increased to where the majority are engaged in these types of activities. The promotion and tenure policies of many institutions do not appear to reflect this important development in faculty efforts. In some university systems, full-time academic appointments have time limits on levels of academic appointment even in the non-tenure stream, such that

\section{Table 1. Institutions included in this study}

1. Boston University Henry M. Goldman School of Dental Medicine

2. Creighton University School of Dentistry

3. Georgia Regents University School of Dental Medicine

4. Howard University College of Dentistry

5. Temple University Maurice H. Kornberg School of Dentistry

6. University of California, San Francisco School of Dentistry

7. University of Illinois at Chicago College of Dentistry

8. University of lowa College of Dentistry

9. University of Manitoba Faculty of Dentistry

10. University of Michigan School of Dentistry

11. University of Mississippi School of Dentistry

12. University of Nebraska Medical Center College of Dentistry

13. University of North Carolina at Chapel Hill School of Dentistry

14. University of Pennsylvania School of Dental Medicine

15. University of Pittsburgh School of Dental Medicine

16. Wake Forest University Medical Center if one cannot advance to the next level of promotion, then he or she is forced to be reclassified and/or be removed from the academic appointment. These types of systems are sometimes referred to as "up or out." 32

Some university systems have modified their tenure time clock and evaluation systems to include an extended pre-tenure probationary period for clinician-educators. ${ }^{2}$ This may be a ten-year tenure timetable instead of the typical five- or seven-year time frame, permitting educators with a high level of commitment to clinical duties to have additional time to develop their research and scholarly activities. Given the changes that have occurred in academia and in clinical health-oriented institutions specifically, the rigidity of tenure timetables needs to be reassessed to determine if they are in the best interests of institutions and their faculties. These types of arrangements are referred to in this article as hybrid tracks in contrast to the traditional non-tenure or tenure tracks. The development of these hybrid tracks has occurred by necessity at a number of academic medical centers and health science universities. ${ }^{3,12,18,26}$

\section{Analysis of Promotion and Tenure Tracks}

The policies of dental schools regarding promotion and tenure have been reviewed by previous authors, but those analyses did not focus on the presence of hybrid tracks within these institutions as a tool for advancement. ${ }^{31-35}$ As an initial step in reviewing policies in North American dental schools regarding the hybrid track for clinician-educators, we analyzed promotion and tenure policies for fifteen dental schools and one medical school (Table 1). These schools constituted a convenience sample for our study, selected because they were the parent institutions of current and previous participants in the ADEA Leadership Institute. We analyzed these institution's documents regarding the information provided on various tracks and mechanisms of promotion and tenure. We identified common mechanisms and themes and categorized programs based on the presence or absence of promotion tracks for scientists, clinicians, or others as well as tenure tracks for each of these categories.

Our review of institutional policies was supplemented with discussions, conducted on a more informal basis, to help us understand the current environment of promotion tracks in North American dental schools. We asked for comments from the 
ADEA Leadership Institute faculty regarding the existence of traditional or non-traditional tracks in their own institutions such as clinician-educator tracks or extended tenure options for faculty members. We also talked with present and past participants in the Leadership Institute and from their parent institutions in an attempt to understand differing views on such faculty roles as high-producing clinician, primary administrator, full-time researcher, faculty transitioning from private practice, and the increasingly rare "triple threat" individual who excels at research, teaching, and clinical production. We then analyzed these comments for common themes.

Of the sixteen institutions included in our study, eleven ( 69 percent) had traditional two-track systems consisting of tenure and non-tenure tracks. Four of these had subtracks that distinguished clinical faculty members from others, but were essentially traditional tracks with slightly different nomenclature. Four of the institutions did have a tenure-track option for non-researcher educators who spent the majority of their time on clinical, administrative, and/or teaching duties. Our review of university policies found that while some dental schools have attempted to develop hybrid tracks, they appear to be less common and have been slower to develop compared with schools of medicine.

However, promotion options were plentiful among these institutions. Some had as many as six separate tracks to ensure that educators had clear guidelines for promotion. Beyond the traditional two-track system, hybrid tracks that included clear guidelines for promotion for educators with primarily clinical and/or teaching activities were present in seven (44 percent) dental schools. Only two (12 percent) of the institutions had clearly stated extended time clock options for clinical-educator faculty to attain tenure, such as a ten-year tenure stream or other extension of time mechanism. A time clock for promotion was present at some institutions but not all. Clinical faculty members who did not qualify for promotion and extended beyond their academic appointment level had the option of being reclassified as adjunct clinical faculty members or a similar visiting status. None of the policies were prescriptive with regard to specific metrics that would be suitable for tenure or promotion. Rather, in all, the policies described broad guidelines for achievement and corresponding levels of recognition. Significant flexibility existed to allow for differences between disciplines to be interpreted through a common evaluation system, such as a committee of peers.
We found some common themes in the discussions regarding concepts of relative value of various activities such as teaching professional and graduate students, high volume clinical practice tied to teaching residents and students, and acquisition of research dollars. Not surprisingly, at all institutions, success in the research arena was highly valued in the promotion and tenure process, and repeated grant support was a key metric. Clinically active individuals were most often considered non-tenure track and were labeled clinical faculty members who were eligible for promotion if they excelled in a scholarly way in teaching and clinical care.

Institutions with hybrid tracks for clinicianeducators had a more explicit emphasis in their policies on measuring teaching activities, innovation in teaching, clinical excellence, innovation in patient care, and other related scholarly activities. This provided the faculty members at those institutions with a more lucid view of the types of activities the university would recognize as scholarly to support their promotion or acquisition of tenure. In several of these institutions, the concept of a faculty portfolio was part of the early mentoring process and helped to provide a roadmap to acquiring tenure and/or promotion.

\section{Arguments Against Hybrid Tracks}

One argument against the use of hybrid tracks is that these mechanisms might "cheapen" the academic integrity of promotion and/or tenure in a way that makes the clinical associate professor seem to be of lesser intrinsic value than the associate professor in the tenure stream. Universities and their administrators can alleviate this discrimination by setting the tone appropriately and rewarding faculty members based on their scholarly contributions. The concept behind creating hybrid tracks is to elevate clinical, professional, and administrative service and teaching contributions to the same level as those based on successfully acquiring research grants. Innovation and contributions in both arenas have value to a university, and an equitable promotion and tenure system encourages this equity across the university. This may be difficult in traditional research universities that have the primary goal of attaining the highest funding levels from the NIH and similar agencies. However, we contend that, to serve the mission of 
the university within the health sciences, equal value must be given to contributions made in a scholarly way as Boyer described. ${ }^{8}$

The same is often said about extended tenure options for clinician-educators that provide them with more time in an "up or out" system. The logic is that busy clinicians charged with teaching students and residents may not have sufficient dedicated time to allow for building a research program and to become independently funded within five to seven years. Additional time may provide an important element to enable faculty members to reach levels of scholarship otherwise unattainable. The effectiveness of these programs can be enhanced if mentoring is in place to avoid overcommitment to clinical duties to the neglect of long-term research objectives to attain tenure in a ten-year time period. Various forces in an institution can encourage a faculty member to become busier clinically, thereby limiting his or her potential in the research arena. Regular mentorship and appropriate incentive mechanisms can alleviate this problem. Linking significant rewards to academic scholarship rather than preferentially encouraging production of clinical revenue can incentivize scholarly activity as well as reward clinical revenue production.

\section{Future Implications of Changes in Promotion and Tenure Systems}

There are a number of potential implications of utilizing hybrid tracks within dental education including faculty recruitment and retention, academic parity for talented and valuable clinician-educators, mentorship and portfolio building, appropriate reward mechanisms, and encouragement of scholarly activity. The extended shortage of faculty members in dental schools has been well documented and discussed. ${ }^{36,37}$ If we are to cultivate new dental academicians and retain valuable educators, utilizing flexible mechanisms for promotion and tenure that serve to facilitate advancement is in the best interest of our institutions. Providing mentoring that focuses on these mechanisms so faculty members are empowered to reach their goals will serve to attract and retain future faculty. ${ }^{5}$

Many medical schools have adopted clinicianeducator tracks because of their high percentages of faculty members who generate much-needed rev- enue to support the academic mission. By necessity, these tracks were created to encourage scholarship and validate the scholarly activity of some faculty members who are seen as important resources for the education of students, residents, and fellows. Some universities offer hybrid tracks to clinician-educators in medicine but not in dentistry. A number of dental schools are in discussions with their governing bodies in attempts to move toward hybrid tracks, and we believe these options should be pursued aggressively by dental school administrators.

Hybrid tracks are helpful for deans and administrators of dental schools to facilitate the development of clinician-educators and those academicians not engaged in research as their primary activity. As Boyer and others have suggested, scholarship in four areas related to the application, discovery, innovation, and integration of knowledge will lead to meaningful and sustained advances in teaching and clinical care in the health sciences. As these outcomes will have significant value for the university and the societies they serve, these activities should be rewarded on the same playing field as those who produce exemplary scholarship in basic science. ${ }^{1,8}$ While universities may differ in their priorities and weigh research, service, and teaching differently, the flexibility of the hybrid mechanisms is such that these tracks are applicable to any institution in an effective way. These mechanisms serve to reward exemplary work and create appropriate advancement for faculty members that have scholarly activity embedded within their teaching and clinical service.

Hybrid tracks also reward exemplary scholarship in a more clear and equitable fashion for those clinicians who are not in the tenure stream. By rewarding clinician-educators in an appropriate manner and expecting appropriate scholarship, the barriers sometimes experienced between the tenure stream basic science faculty members and non-tenure stream clinical faculty members will be easier to dispel. Interdisciplinary and translational science may be easier to facilitate by utilizing these mechanisms because scholarly activity associated with clinical translation of basic science principles can be measured and rewarded appropriately.

There are potential drawbacks to adopting a modified promotion and tenure system, including one report of negative experiences encountered in implementing these types of promotion and tenure mechanisms based on the Boyer philosophy of scholarship. ${ }^{38}$ Even in this case though, there was 
a realization that scholarly activity was necessary across multiple arenas, and a flexible and effective system of evaluation and awarding advancement is essential. However, if the system is not organized and implemented well, it will fail. Unfortunately, little data have been published on the measurable outcomes of these hybrid tracks and whether they have significant positive or negative effects on scholarly activity, retention of faculty, or improvements in faculty satisfaction. ${ }^{9,31,32,38}$ With the many varieties of hybrid tracks, these mechanisms should be studied to gauge their effectiveness-particularly in the areas of retention, faculty satisfaction, and encouragement of scholarly activity.

There is inevitable resistance to change and particularly to change that affects longstanding principles of scholarly activity at research universities. Trustees, university presidents, provosts, deans, and others will continue to debate the merits of hybrid tracks and traditional tenure. We contend that while dental schools have inherent differences when compared with other schools such as engineering or liberal arts, the main principles of scholarly activity can and should be applied similarly, as described by Boyer. ${ }^{8,17,39}$ The scholarly activities that academic dentists find themselves engaged in are important to the mission of their schools and the university system. Having mechanisms for clinician-educators that foster scholarship and reward academic success should help to retain faculty by providing a clear path to success and engendering professional development.

\section{Conclusion}

Hybrid tracks for promotion and tenure exist in many forms in health professions schools and can serve to encourage and reward scholarly activity in a variety of arenas, particularly for the clinicianeducators who are ubiquitous at dental schools. Hybrid tracks may also be utilized as mentoring opportunities to help set the path and build a portfolio for these faculty members so that they may clearly visualize and achieve advancement. Deans and other administrators are charged in part with advocating for the faculty at their schools. We maintain that hybrid tracks should be made available at dental schools to facilitate scholarly activity in the application, discovery, integration, and teaching of knowledge that forms the basis for dental education and patient care. In the current environment, it is critical to consider superior scholarly work in clinical care and teaching as a part of promotion and tenure. Universities should support these mechanisms for advancement at dental schools as they have for many medical schools. Dental school administrators, and particularly department chairs, should utilize these mechanisms to enable advancement of their clinically active faculty members and also to foster a new vision of scholarly activities that facilitate achievement of institutional missions in the current societal and academic environments. In addition to conceptualization and articulation of these guidelines, institutions should map out plans to facilitate individual faculty success with mentoring designed to highlight the types of scholarly activity necessary to gain promotion and tenure. Faculty members who do not see a clear path to advancement are more likely to experience dissatisfaction.

We believe it is essential for institutions to develop promotion and tenure guidelines for hybrid and other tenure tracks that are congruent with institutional missions and the effort distributions required of faculty members. It is critical for institutions to help individual faculty members develop a roadmap for success to achieve promotion and/or tenure, and it is also important to incorporate flexibility for evaluators as they interpret scholarly activities amongst a varied faculty. In addition to developing promotion and tenure guidelines that reflect the current realities of health professions education, institutions must also develop more effective mentoring and development of faculty members to help them fulfill requirements for advancement in their particular settings. Hybrid tracks empower faculty members to successfully perform scholarly activities that realistically reflect institutional missions. While developing such progressive mechanisms at dental schools will foster scholarly activity, institutions must effectively communicate to junior faculty members how to navigate the promotion and tenure process. Institutions can no longer afford the paradigm of leaving the success of new faculty members to chance and self-directed development.

Institutions must identify how vital activities performed by clinician-educators can be elevated to the level of scholarship and provide mechanisms to measure these activities. Specific suggestions include the following:

1. Establish congruence of institutional mission, faculty activities, and promotion and tenure guidelines utilizing a hybrid mechanism.

2. Develop and clarify concepts of scholarly activities germane to a faculty member's clinical, teaching, and research activities in the spirit of Boyer's expanded concept of scholarship. 
3. Increase the promotion and tenure probationary period to ten years, or develop a more flexible time clock to permit attainment of successful promotion and tenure for those faculty members who have significant commitments outside of the research arena.

4. Provide a supportive faculty development, mentoring, and resource allotment to enable clinicians, teachers, and researchers to develop and measure scholarly activities.

5. Provide reward mechanisms tied to the promotion and tenure process that are equitable and based on scholarly achievement.

6. Develop infrastructure to provide ongoing assessment of promotion and tenure guidelines to ensure that they reflect changes in mission and faculty activities.

\section{REFERENCES}

1. Lubitz RM. Guidelines for promotion of clinician-educators. J Gen Intern Med 1997;12(Suppl 2):S71-8.

2. Liu M, Mallon WT. Tenure in transitions: trends in basic science faculty appointment policies at U.S. medical schools. Acad Med 2004;79(3):205-13.

3. Barchi RL, Lowery BJ. Scholarship in the medical faculty from the university perspective: retaining academic values. Acad Med 2000;75(9):899-905.

4. Smesny A, Williams J, Brazeau G, Weber R, Matthews $\mathrm{H}$, Das S. Barriers to scholarship in dentistry, medicine, nursing, and pharmacy practice faculty. Am J Pharm Educ 2007;71(5):1-9.

5. Oakley M, Vieira AR. The endangered clinical teacherscholar: will this eliminate discovery from the dental school environment? J Dent Res 2008;87(3):200-2.

6. Glassick CE, Huber MT, Maeroff GI. Scholarship assessed: evaluation of the professoriate. San Francisco: Jossey-Bass, 1997.

7. Beattie DS. Expanding the view of scholarship: introduction. Acad Med 2000;75(9):871-6.

8. Boyer E. Scholarship reconsidered: priorities of the professoriate. Princeton: The Carnegie Foundation, 1990.

9. Trotman CA, Haden NK, Hendricson W. Does the dental school work environment promote successful academic careers? J Dent Educ 2007;71(6):713-25.

10. Glick TH. How best to evaluate clinician-educators and teachers for promotion? Acad Med 2002;77(5):392-7.

11. Tedesco L, Martin M, Banday N, Clarke M, DeChamplain R, Fazekas A, et al. Scholarship and the university. Eur J Dent Educ 2002;6(Suppl 3):86-96.

12. Coates WC, Hobgood CD, Birnbaum A, Farrell SE. SAEM Undergraduate Education Committee. Faculty development: academic opportunities for emergency medicine faculty on education career tracks. Acad Emerg Med 2003;10(10):1113-7.

13. Purcell N, Lloyd-Jones G. Standards for medical educators. Med Educ 2003;37(2):149-54.

14. Farrell SE, Digioia NM, Broderick KB, Coates WC. Mentoring for clinician-educators. Acad Emerg Med 2004;11(12):1346-50.
15. Simpson D, Marcandante K, Duthie E Jr, Sheehan K, Holloway R, Towne J. Valuing educational scholarship at the Medical College of Wisconsin. Acad Med 2000;75(9):930-4.

16. Socolar RR, Kelman LS, Lannon CM, Lohr JA. Institutional policies of U.S. medical schools regarding tenure, promotion, and benefits for part-time faculty. Acad Med 2000;75(8):846-9.

17. Braxton JM, Luckey W, Helland P. Institutionalizing a broader view of scholarship through Boyer's four domains. ASHE-ERIC Higher Education Report. San Francisco: Jossey-Bass/John Wiley, 2002.

18. Levinson W, Rubenstein A. Mission critical: integrating clinician-educators into academic medical centers. N Engl J Med 1999;341(11):840-3.

19. Hafler J, Lovejoy F. Scholarly activities recorded in the portfolios of teacher-clinician faculty. Acad Med 2000;75(6):649-52.

20. Malinsky 1, DuBois R, Jacquest D. Building scholarship capacity and transforming nurse educators' practice through institutional ethnography. Int J Nurs Educ Scholarsh 2010;7(1):1-12.

21. Cameron J. Williams Stewart Halsted: our surgical heritage. Annals Surg 1997;225(5):445-58.

22. Flexner A. Medical education in the United States and Canada. New York: Carnegie Foundation for Higher Education, 1910.

23. Gies WJ. Dental education in the United States and Canada: a report to the Carnegie Foundation for the Advancement of Teaching. New York: Carnegie Foundation, 1926.

24. Drisko CL, Whittaker LP. Dental school faculty and the academic environment from 1936 to 2011: familiar features in a new context. J Dent Educ 2012;76(1):65-74.

25. Rosenberg L. Physician-scientists: endangered and essential. Science 1999;283(5400):331-2.

26. Bickel J. The changing faces of promotion and tenure at U.S. medical schools. Acad Med 1991;66(5):249-56.

27. Shepherd K, Nihill P, Botto R, McCarthy M. Factors influencing pursuit and satisfaction of academic dentistry careers: perceptions of new dental educators. J Dent Educ 2001;65(9):841-8

28. Kahn C, Huberman G. Two-sided uncertainty and "upor-out" contracts. J Labor Econ 1988;6:423-44.

29. McPherson MS, Shapiro M. Tenure issues in higher education. J Econ Perspect 1999;13(1):85-98.

30. Shih E. Transient professors: how important is tenure? The Yale Herald, 2003.

31. Peterson MR. Academic tenure and higher education in the United States: implications for the dental education workforce in the twenty-first century. J Dent Educ 2007;71(3):354-64.

32. Plicher ES, Kilpatrick AO, Segars J. An assessment of promotion and tenure requirements at dental schools. J Dent Educ 2009;73(3):375-82.

33. Scheetz JP, Mendel RW. Tenure in U.S. and Canadian dental schools. J Dent Educ 1982;46(2):68-73.

34. Mayhew RB, Van Stewart A. Review of current tenure policies and their relation to junior dental faculty. J Dent Educ 1998;62(4):302-6. 
35. Hunt RJ, Gray CF. Faculty appointment policies and tracks in U.S. dental schools with clinical or research emphases. J Dent Educ 2002;66(9):1038-43.

36. American Dental Education Association. Trends in dental education. Washington, DC: American Dental Education Association, 2006.
37. Okwuje I, Sisson A, Anderson E, Valachovic RW. Dental school vacant budgeted faculty positions, 2007-08. J Dent Educ 2009;73(12):1415-22.

38. Schweitzer L. Adoption and failure of the Boyer model at the University of Louisville. Acad Med 2000;75(9):925-9.

39. Highberg NP. Ernest L. Boyer and the scholarship of integration. Chronicle of Higher Education, July 10, 2010. 